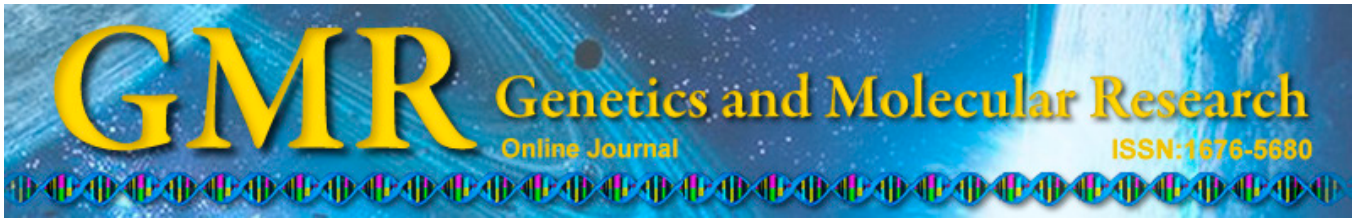

\title{
Expression profiles of DNA repair-related genes in rat target organs under subchronic cadmium exposure
}

\author{
Y.X. Lei, Q. Lu, C. Shao, C.C. He, Z.N. Lei and Y.Y. Lian \\ School of Public Health, Guangzhou Medical University, Guangzhou, China \\ Corresponding author: Y.X. Lei \\ E-mail: yixionglei@yeah.net
}

Genet. Mol. Res. 14 (1): 515-524 (2015)

Received December 18, 2013

Accepted April 29, 2014

Published January 26, 2015

DOI http://dx.doi.org/10.4238/2015.January.26.5

\begin{abstract}
We aimed to evaluate the toxicity of long-term exposure to different cadmium $(\mathrm{Cd})$ doses in rats and expression profiles of DNA repair-related genes. The model rats were exposed to different concentrations of $\mathrm{CdCl}_{2}$ for 3 months, and 5 DNA repair-related genes - hMSH2, MLH1, XRCC1, hOGG1, ERCC1 - were cloned in different tissues, including the liver, kidney, heart, and lung. Accumulated amounts of $\mathrm{Cd}$ were detected in the tissues. Gene and protein detections were conducted via fluorescence quantitative realtime polymerase chain reaction and Western blotting, respectively. Methylated sequences of the 5 DNA repair-related gene promoters were used to investigate whether the low expression levels of the genes were related to methylation of the promoter. In the Cd-exposed group, 3 DNA repair genes (i.e., $X R C C 1, h O G G 1$, and $E R C C l$ ) significantly decreased in the rat liver, kidney, heart, and lung according to the $\beta$-actin internal standard $(\mathrm{P}<0.01)$. Western blotting indicated the same trend for the different tissues. Each of the DNA repair genes had special characteristics; for example, $h O G G 1$ gene expression decreased by $75 \%$ in the kidney, and $X R C C 1$ gene expression decreased by $5 \%$ in the liver and heart when compared to the control group $(\mathrm{P}<0.01)$.
\end{abstract}


A negative correlation between the DNA repair gene expression levels and the cumulative levels of $\mathrm{Cd}$ was also suggested by malignancy pathology. The expression levels of 3 DNA repair genes (i.e., ERCC1, $X R C C 1$, and $h O G G 1$ ) played an important role in the rat response to $\mathrm{Cd}$ exposure but not DNA methylated protection.

Key words: Cadmium exposure; DNA repair gene; DNA methylation; Subchronic toxicity

\section{INTRODUCTION}

Cadmium (Cd) and its compounds are occupational hazardous chemicals and environmental contaminants, and they can induce a wide variety of adverse health effects, even causing animal and human tumors (Satarug et al., 2003; Waalkes, 2003; Swaddiwudhipong et al., 2010). The toxicological reactions of exposure to Cd include solid organ damage, respiratory disease, neurological disorders, and bone disease (Nordberg et al., 2002; Koyu et al., 2006; Schöpfer et al., 2010). In view of its epidemiological and experimental studies, $\mathrm{Cd}$ and its compounds were classified as human carcinogens in 1993 by the International Agency for Research on Cancer (IARC, 1993).

However, the pathogenic mechanism underlying toxicity of the target organ has not been thoroughly investigated, to date. More and more scientists have grown concerned with the toxicological mechanisms related to long-term exposure to low doses of Cd. Waalkes (2003) found that $\mathrm{Cd}$ and its compounds produced genotoxic and non-genotoxic epigenetic components via experimental and epidemiological data (Waalkes and Poirier, 1984; Misra et al., 1998; Klaassen et al., 1999; Kasprzak et al., 2002). In researching the processes of cell biology, several studies have demonstrated that specific DNA repair genes exhibit low levels of expression in some Cd-exposed cell lines (Singh et al., 2009; Zhou et al., 2012). Al Bakheet et al. (2013) reported the effect of long-term human exposure to environmental heavy metals on the expression of detoxification and DNA repair genes. Simultaneously, the expression profiles and potential mechanisms of DNA repair genes in solid target organs of rats subchronically exposed to $\mathrm{Cd}$ have been a primary focus of research. Our department established the rat model for evaluating subchronic exposure to $\mathrm{Cd}$ in 2013 (Lu et al., 2013). In this study, we tested the expression profile of DNA repair-related genes [i.e., hMSH2, $M L H 1$, X-ray repair cross complementing group 1 (XRCC1), hOGG1, and ERCCl] in rat target organs (i.e., the liver, kidney, heart, and lung) that were disposal to $\mathrm{CdCl}_{2}$ at different concentrations. We wanted to explore if the low level of expression of specific DNA repair genes could be a detection index for toxic effects during long-term exposure to low doses of $\mathrm{Cd}$ in vivo.

In the field of epigenetics, DNA methylation plays an important role in the DNA damage repair process. Thus, we analyzed DNA methylation sequencing to inspect whether the alterative expressions of the DNA repair genes resulted from promoter methylations.

\section{MATERIAL AND METHODS}

\section{Animal experiments}

The rat model of subchronic $\mathrm{Cd}$ exposure was previously established by our research 
team, and the results were reported (Lu et al., 2013). Forty-eight Sprague-Dawley rats were randomly divided into 4 groups (12 rats per group). The rats were supplied by the Guangdong Medical Laboratory Animal Center.

The concentrations of the intraperitoneal (ip) injection doses for three independent experiments were as follows: 1) low at $1.225 \mathrm{mg} / \mathrm{kg}$, 2) medium at $0.612 \mathrm{mg} / \mathrm{kg}$, and 3) high at $0.306 \mathrm{mg} / \mathrm{kg}$. Simultaneously, the control group received ip injections with $09 \% \mathrm{NaCl}$. The injections were administered 5 times per week. Rats were sacrificed after 14 weeks of injections, and the target organs were collected (i.e., the liver, kidney, heart, and lung) and stored in liquid nitrogen. The accumulated levels of $\mathrm{Cd}$ in the tissues were assessed using atomic absorption spectrometry (ZEENIT700, Analytik Jena, Jena, Germany). Pathological examinations were conducted following fixation of fresh tissues with $10 \%$ formalin in accordance with the protocol for standard hematoxylin and eosin staining.

All animal experiments were conducted under the supervision of the Animal Experimental Ethics Committee of Guangzhou Army General Hospital (Guangzhou, China).

\section{Reverse transcription-polymerase chain reaction (RT-PCR)}

The TRIzol kit (Invitrogen, CA, USA) was used to extract total RNA from 50 to 100 mg tissues. The RNA was eluted into $50 \mu \mathrm{L} \mathrm{H}_{2} \mathrm{O}$. The PrimeScript RT reagent Kit (Promega, WI, USA) was used to reverse transcriptase RNA to complementary DNA according to the manufacturer protocol.

Subsequently, the target DNA repair genes were determined by real-time PCR using the PE 7000 Sequence Detection System (ABI PRISM, USA), with $\beta$-actin as an internal standard. PCR was performed by using the primers that are illustrated in Table 1 . The PCR mixtures were treated for $10 \mathrm{~min}$ at $42^{\circ} \mathrm{C}$, then $2 \mathrm{~min}$ at $93^{\circ} \mathrm{C}$ and 40 cycles of amplification as follows: denaturation at $93^{\circ} \mathrm{C}$ for $45 \mathrm{~s}$ and renaturation at $55^{\circ} \mathrm{C}$ for $45 \mathrm{~s}$. The fluorescence signal was collected at the renaturation step.

Table 1. Primers for target DNA repair genes and fragment sizes by real-time polymerase chain reaction.

\begin{tabular}{llc}
\hline Target genes & Primer sequences & Size (bp ) \\
\hline hMSH2 & Forward: 5'-TGCTCAAGGACAAAGGCTG-3' & 150 \\
& Reverse: 5'-GGAAATCGGCGAAGTAAATC-3' & 215 \\
& Forward: 5'-GTGCTGGCAATCAAGGGACCC-3' & 76 \\
XRCC1 & Reverse: 5'-CACGGTTGAGGCAATGGGTAG-3' & 76 \\
hOGG1 & Forward: 5'-TTCACAGCCCTCCAGACAAAG-3' & 432 \\
& Reverse: 5'-CGGAACTGGCCGAGCTT-3' & \\
ERCC1 & Forward: 5'-CTGCCTTCTGGACAATCTTT-3' & 138 \\
$\beta$-actin & Reverse: 5'-TAGCCCGCCCTGTTCTTC-3' & 172 \\
& Forward: 5'-AAG GCG TAT GAG CAG AAG C-3' \\
\hline
\end{tabular}

\section{Western blotting analysis}

The protein expressions of DNA repair-related genes were detected by Western blotting. The tissue protein extraction kit (Thermo, USA) was used to extract total protein from 50 $\mathrm{mg}$ tissues. The Western blotting steps were as follows: 1) $50 \mu \mathrm{g}$ total protein was electropho- 
resed on $12.5 \%$ SDS-PAGE; 2 ) the samples were then transferred to polyvinylidene fluoride membranes; 3 ) blocking was initiated with 5\% skim milk; 4) incubation was conducted with primary antibodies after washing in TTBS overnight at $4{ }^{\circ} \mathrm{C}$ [the primary antibodies included the $h M S H 2, M L H 1, X R C C 1, h O G G 1, E R C C 1$, and glyceraldehyde-3-phosphate dehydrogenase (GAPDH) antibodies]; and 5) linkage to $5 \mathrm{~mL}$ HRP-conjugated goat anti-rabbit $\operatorname{IgG}$ before initiation of the chromogenic reaction. The Western blotting protein bands were calculated using GAPDH as the internal standard and an enhanced chemiluminescence system ( Bestbio, China).

\section{DNA methylation detection}

A DNeasy Blood and Tissue Kit (Qiagen, Hilden, Germany) was used to extract total DNA from $50 \mathrm{mg}$ tissues according to the operation manual. DNA methylation was used to sequence the promoter regions of 5 DNA repair genes. The methods utilized were in accordance with reduced representation bisulfite sequencing (RRBS).

\section{Statistical analysis of data}

All data are reported as means \pm SD of 4 independent experiments in 48 SpragueDawley rats. The data were changed into normal distribution with a logarithm if the original data were positively skewed in distribution. Differences among the experimental groups, and correlations among the expression levels of the DNA repair genes, $\mathrm{Cd}$ concentrations, and pathological features for the various target organs were analyzed. If the data were homogenous, ANOVA, Student-Newman-Keuls, and Pearson's correlation were calculated. If the data were not homogenous, the Kruskal-Wallis, ANOVA, Games-Howell test, and Spearman's correlation analysis were calculated. All analyses were conducted using the SPSS 17.0 software (SPSS Inc., Chicago, IL, USA). Values $<0.05$ were considered to be statistically significant.

\section{RESULTS}

\section{Identification of RT-PCR}

After RT and fluorescence real-time PCR amplification, by Rn fluorescence collection, the cycle threshold $(\mathrm{Ct})$ of the target gene was in the range of 26.00-27.00. Meanwhile, the $\beta$-actin $\mathrm{Ct}$ was in the range of 31.00-32.00. Thus, the 5 DNA repair-related genes were widely represented in rats. There was one single peak with melt, indicating that nonspecific products were not present.

Figure 1 demonstrates that the 5 RNA changes were accompanied by changes in $\mathrm{Cd}$ concentrations. In the experimental group exposed to $\mathrm{Cd}$ in a dose-dependent manner, when compared to the control group, 3 special DNA repair genes (i.e., XRCC1, hOGG1, and $E R C C 1)$ significantly decreased in the rat tissues of the liver, kidney, heart, and lung, according to the $\beta$-actin internal standard $(\mathrm{P}<0.01)$.

However, in the different tissues, the expression levels of the $h M S H 2$ and $M L H 1$ genes were not significantly different between the experimental and control groups. 
A
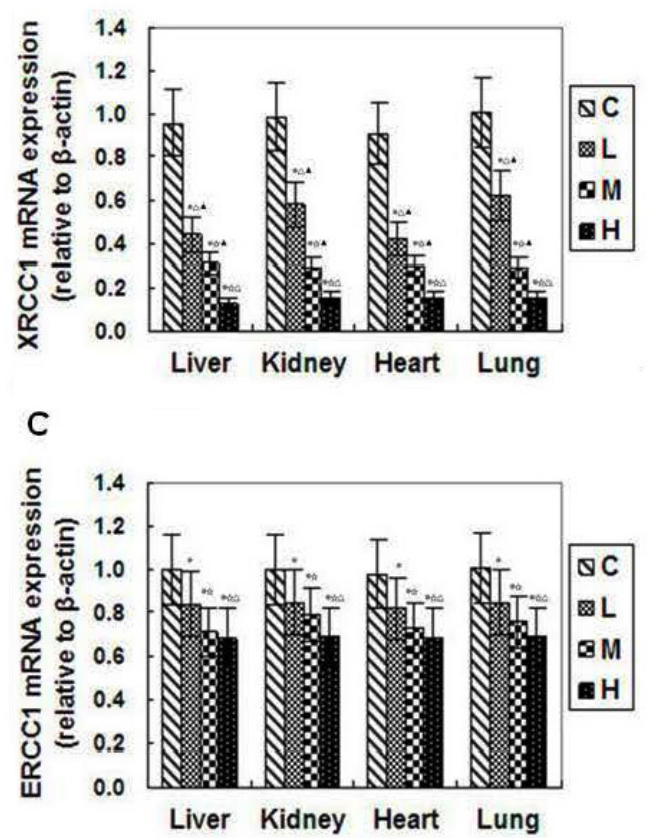

B

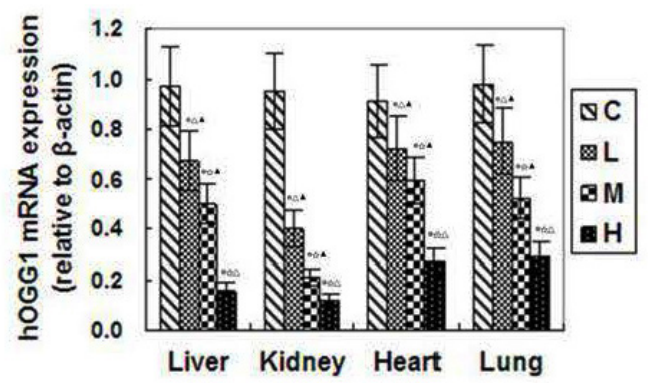

Figure 1. Five specific RNA changes accompanied by concentration changes of cadmium $(\mathrm{Cd})$ in different tissues (relative to $\beta$-actin). $\mathrm{C}=$ control; $\mathrm{L}=$ low-dose of $\mathrm{Cd}$ exposure; $\mathrm{M}=$ mid-dose of $\mathrm{Cd}$ exposure; $\mathrm{H}=$ high-dose of $\mathrm{Cd}$ exposure. Data are reported as means \pm standard deviation (SD). ${ }^{*} \mathrm{P}<0.01$ compared to the control group $(0.9 \%$ $\mathrm{NaCl}) ; * \mathrm{P}<0.01$ compared to the low-dose group $(0.306 \mathrm{mg} / \mathrm{kg}) ;{ }^{\Delta} \mathrm{P}<0.01$ compared to the mid-dose group $(0.612$ $\mathrm{mg} / \mathrm{kg})$; and $\Delta \mathrm{P}<0.01$ compared to the high-dose group $(1.225 \mathrm{mg} / \mathrm{kg})$ based on ANOVA, followed by GamesHowell comparison.

\section{RNA expression decreases with $\mathrm{Cd}$ in different tissues}

After RT-PCR amplification, we calculated the RNA expression of DNA repair genes in different tissues with $\beta$-actin as an internal standard. At the same time, the $\mathrm{Cd}$ accumulation levels in the tissues were measured by atomic absorption spectrometry. Figure 2 illustrates the negative correlations between low levels of expression of XRCC1, hOGG1, and $E R C C 1$ with high levels of $\mathrm{Cd}$ accumulation $(\mathrm{P}<0.05) . X R C C 1$ expression levels exhibited a negative correlation with $\mathrm{Cd}$ accumulation in the liver $(\mathrm{r}=0.610, \mathrm{P}<0.05)$, kidney $(\mathrm{r}=$ $0.598, \mathrm{P}<0.05)$, heart $(\mathrm{r}=0.527, \mathrm{P}<0.05)$, and lung $(\mathrm{r}=0.633, \mathrm{P}<0.05) . h O G G 1$ expression levels exhibited a negative correlation with $\mathrm{Cd}$ accumulation in the liver $(\mathrm{r}=0.610, \mathrm{P}<$ $0.05)$, kidney $(\mathrm{r}=0.598, \mathrm{P}<0.05)$, heart $(\mathrm{r}=0.527, \mathrm{P}<0.05)$, and lung $(\mathrm{r}=0.633, \mathrm{P}<0.05)$. ERCC1 expression levels exhibited a negative correlation with $\mathrm{Cd}$ accumulation in the liver $(\mathrm{r}=0.610, \mathrm{P}<0.05)$, kidney $(\mathrm{r}=0.598, \mathrm{P}<0.05)$, heart $(\mathrm{r}=0.527, \mathrm{P}<0.05)$, and lung $(\mathrm{r}=$ $0.633, \mathrm{P}<0.05)$.

The DNA repair-related genes $h M S H 2$ and $M L H 1$ had no correlation with changes in Cd concentrations $(\mathrm{P}>0.05)$. 
The low level of expression of the 3 genes (XRCC1, hOGG1, and ERCC1) was significantly consistent with the corresponding malignant pathological changes. Thus, $\mathrm{Cd}$ target organ toxicity and damage were associated with low levels of expression of particular DNA repair genes.

A

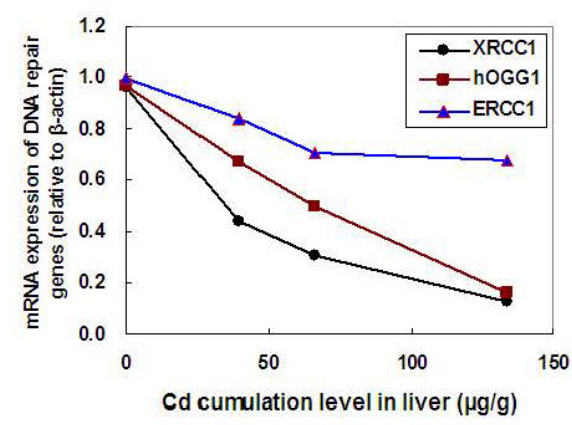

$\mathrm{C}$

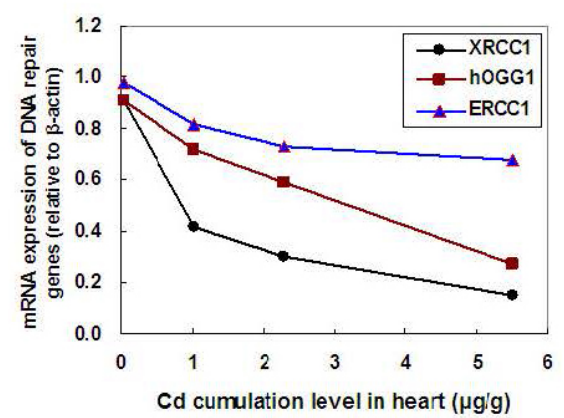

B

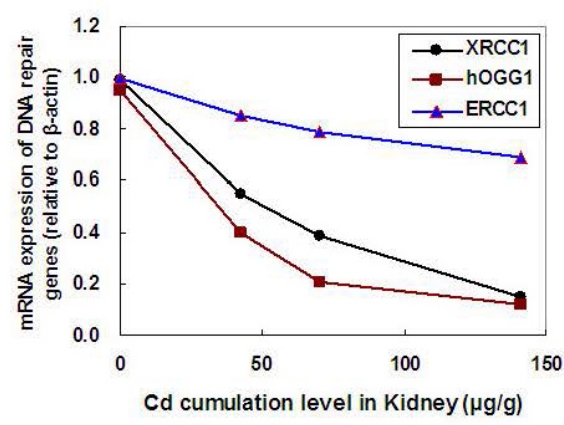

D

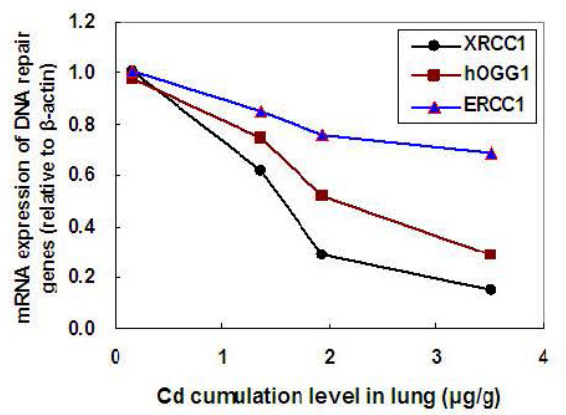

Figure 2. Negative correlations between low expression of $X R C C 1, h O G G 1$, and $E R C C 1$ with high levels of $\mathrm{Cd}$ accumulation in different rat tissues: A. liver; B. kidney; C. heart; D. lung.

\section{Western blotting for proteins}

The results of Western blotting were consistent with the identification of RNA. The proteins of the 3 DNA repair genes (i.e., XRCC1, $h O G G 1$, and ERCC1) declined in the rat liver, kidney, heart, and lung tissues after Cd exposure (Figure 3). In contrast, the proteins of hMSH2 and MLH1 did not change significantly.

After calculating the Western blotting protein bands with GAPDH as the internal standard, maximum variability was observed for the protein hOGG1, which exhibited a $75 \%$ decline in the kidney; the minimum variability (i.e., $50 \%$ decline) was observed for the $X R C C 1$ protein in the liver and heart with low-dose $\mathrm{Cd}$ exposure $(\mathrm{P}<0.01)$.

\section{DNA methylation sequencing}

Using the RRBS method to sequence the 5 DNA repair genes (i.e., hMSH2, MLH1, 
$E R C C 1, X R C C 1$, and $h O G G 1)$ we obtained the promoter sequences in Table 2. A BLAST of the sequences in GenBank showed that they were consistent with the Rattus norvegicus strain of the DNA mismatch repair protein gene, with $100 \%$ identities. The methylation of the DNA repair gene promoters was stably inherited in the $\mathrm{Cd}$ exposure environment.

When compared to the control rat methylated sequences, the methylation levels of the 5 DNA repair gene promoters did not change after exposure to $\mathrm{Cd}$. Analysis of the $\mathrm{CpG}$ islands in the promoters of the 5 DNA repair genes indicated that the 3 special genes (i.e., ERCC1, $X R C C 1$, and $h O G G 1$ ) did not statistically differ from the other genes (i.e., $h M S H 2$ and $M L H 1$ ).

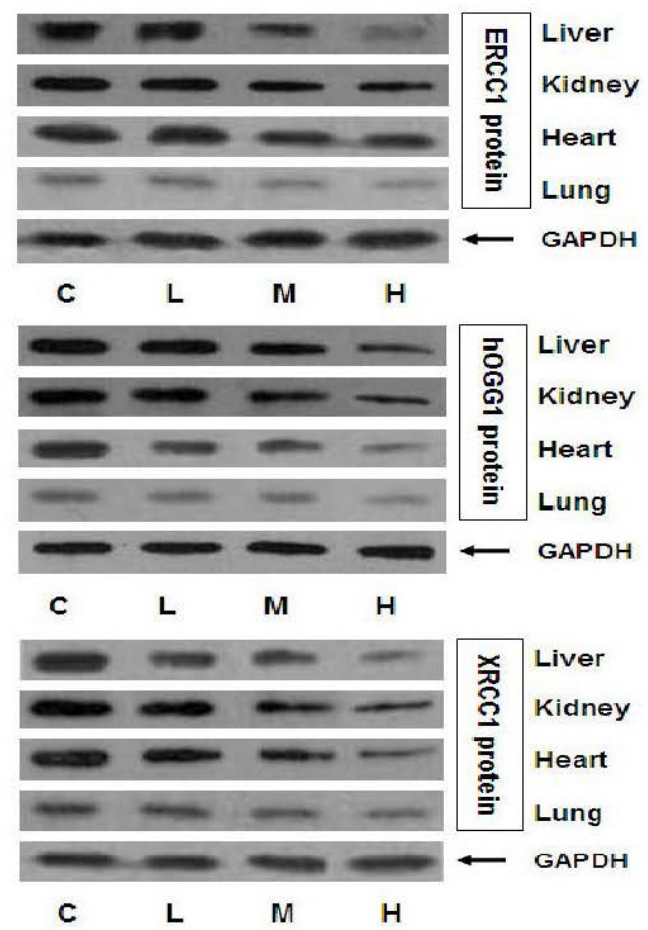

Figure 3. Western blotting results for XRCC1, hOGG1, and ERCC1 proteins in Cd-exposed target tissues. GAPDH was used as an internal standard to calculate the relative protein levels. $\mathrm{C}=$ control; $\mathrm{L}=$ low-dose of $\mathrm{Cd}$ exposure; $\mathrm{M}=$ mid-dose of $\mathrm{Cd}$ exposure; $\mathrm{H}$ = high-dose of $\mathrm{Cd}$ exposure.

Table 2. Methylation DNA sequencing of promoter regions for 5 specific DNA repair genes.

\begin{tabular}{|c|c|c|}
\hline Genes & Promoter region sequences & $\mathrm{CpG}$ island \\
\hline$h M S H 2$ & $\begin{array}{l}\text { CGgttatgattggctattgCGgtagactcccacccaccaaggagcagCGctgcatgctgattgggCGagcccacCGa } \\
\text { ggcCGgaCGCGgtttaggggCGaggttggggaggCGggaaaCGaccCGgCGagCGcagggtcCGgc }\end{array}$ & 15 \\
\hline$M L H 1$ & $\begin{array}{l}\text { CGgacCGtgaactttgaCGCGcaagCGCGttgccttccaaccCGgtgggcagcCGctgtttagggCGgaacag } \\
\text { ataccccaggaactgaCGtaagaggCGattgactggcatttattctgcccaatcagcacttgcCGctgggaaggtggetca } \\
\text { ggaCGgCGgtCGgcccaaggtgaaggaagaacttgCGcttgaggagcc }\end{array}$ & 16 \\
\hline$X R C C 1$ & $\begin{array}{l}\text { gactttggaagCGcaaagggagaacttCGtgggattctgaggggCGcCGCGggtggggtttccCGaggctggaC } \\
\text { GtgcattcCGagagagacCGgcaattagggaagtttggggecactgtgaagagtaag }\end{array}$ & 9 \\
\hline$h O G G 1$ & $\begin{array}{l}\text { tcacaccaaaagcctgaaatggcagagcagggectCGgacagccaatCGccaagcagCGaggccagcagtctaac } \\
\text { CGctcCGgCGcctcagataggecCGcccactctgccactcc }\end{array}$ & 7 \\
\hline ERCC1 & $\begin{array}{l}\text { CGCGaagagttctcCGctctatctcccetggggagcagCGagatgagCGtaggactagagCGgcCGgaagtgag } \\
\text { tttagcaggaggcaCGcctgcCGCGctggcCGtgctggaggtgctggCGttgtatCG }\end{array}$ & 13 \\
\hline
\end{tabular}




\section{DISCUSSION}

It has been reported that $\mathrm{Cd}$ contamination can induce genetic alterations and lead to organ damage. Waisberg et al. (2003) found evidence of the molecular and cellular mechanisms of Cd carcinogenesis in cell lines and animals. IARC (1993) assessed Cd as a suspected carcinogen. It can cause acute pulmonary edema and chemical pneumonia. Individual cases may be associated with liver and kidney damage. In 2012, Cd pollution incidents occurred in GuangXi Longjiang River; in 2009, pollution incidents also occurred in Hunan Liuyang. Thus, $\mathrm{Cd}$ pollution should be prevented worldwide, particularly in developing countries.

The DNA repair genes play important roles in maintaining the stability of the genome, and the inhibition of DNA repair might be one of the important mechanisms responsible for $\mathrm{Cd}$ carcinogenesis (Zhou et al., 2012). More than 130 DNA repair genes have been cloned. They play roles in base excision repairing (BER), nucleotide excision repairing (NER), mismatch repairing, direct repairing, and double-strand break repairing. The defects in DNA repairing could induct genetic instability or individual cancer. The 5 DNA repair-related genes $(h M S H 2$, $M L H 1, E R C C 1, X R C C 1$, and $h O G G 1)$ were related to the occurrence and development of cancer, which has been reported worldwide (Potts et al., 2001; Benbrahim-Tallaa et al., 2007; Zhou et al., 2012).

The DNA repair gene $X R C C 1$ plays an important role in the maintenance of genomic integrity and protection of cells from DNA damage. Sequence variation in the $X R C C 1$ gene may alter head and neck cancer susceptibility. XRCC1 can repair DNA single-strand breaks and base damage and was a core member of the BER proteins (Bouziane et al., 1998). During the repair process, $X R C C 1$ stabilizes the DNA polymerase $\beta$ and alters the activity of the DNA ligase III, which is involved in the regulation of PARP (Joseph et al., 2004; Zhou et al., 2004). In this study, we observed that the $X R C C 1$ gene and its protein decreased after subchronic $\mathrm{Cd}$ exposure within the rat kidney, heart, lung, and, primarily, the liver. $\mathrm{Cd}$ induced rat hepatocyte hormesis and the accumulation was affected. The data showed that $\mathrm{CdCl}_{2}$ induced malignant transformation of 16HBE cells with low expression of XRCC1 (Zhou et al., 2012). Similar results were also confirmed in the current study.

The human 8-oxoguanine DNA glycosylase $(h O G G 1)$ gene plays an important role in the repair of oxidatively damaged DNA base lesions, and its functional single nucleotide polymorphisms may alter DNA repair capacity and, thus, contribute to cancer susceptibility (Hake et al., 2004). Research shows that Cd can completely inhibit the enzyme activity of animal $h O G G 1$ and increase 8-OHdG in target organs. Thus, 8-OHdG inhibited $h O G G 1$ gene expression (Van Duin et al., 1986; Wang and Xu, 2011).

Excision repair cross-complementation group 1 (ERCC1) is an important protein in the NER pathway, which is responsible for removing DNA adducts induced by platinum-based compounds. The heterodimer ERCC1-XPF is one of 2 endonucleases required for NER. Genetic variations or polymorphisms in the $E R C C 1$ gene alter DNA repair capacity. Reduced DNA repair (i.e., NER) capacity may result in tumors and enhance cisplatin chemotherapy in cancer patients, which functions by causing DNA damage (Lehmann, 1995).

In this study, the expressions of the DNA repair genes ERCC1, XRCCl, and hOGG1 significantly decreased in the liver, kidney, heart, and lung of all rats exposed to $\mathrm{Cd}$ in a dose-dependent manner. Research on the target organs focused on the liver and kidney, where Cd toxins typically exert their effects. However, subchronic and chronic Cd toxicity in the heart and lung have been rarely reported. Moreover, epidemiological data have demonstrated that environmen- 
tal Cd exposure is a risk factor associated with cardiovascular disease (Peters et al., 2010).

Investigations of animal Cd distribution have revealed that $0.2,2$, and $25 \%$ doses of

$\mathrm{Cd}$ were distributed throughout the heart, kidney, and liver, respectively. Thus, the heart might be a model organ for researching Cd accumulation in vivo (Manca et al., 1991; Bhatnagar, 2004). The results of our study indicate that expressions of the XRCC1, hOGG1, and ERCC1 genes were notably regulated at low levels in the heart and lung with exposure to $\mathrm{Cd}$. The data suggest that the heart and lung were also damaged via $\mathrm{Cd}$ toxicity. Our investigation revealed that the low expressions of any DNA repair-related genes (e.g., XRCC1, hOGG1, and ERCC1) caused damage to organs that were subchronically exposed to $\mathrm{Cd}$.

It is now widely recognized that $\mathrm{Cd}$ is a weak mutagen that causes chromosomal aberrations and DNA damage (Hartwig et al., 1998; Fatur et al., 2003). The low levels of expression of 3 genes (i.e., XRCC1, $h O G G 1$, and $E R C C 1$ ) were significantly consistent with the corresponding malignant pathological changes. Thus, $\mathrm{Cd}$ target organ toxicity and damage are associated with low levels of expression of particular DNA repair genes. We hypothesize that Cd causes DNA damage on the one hand and, on the other hand, interferes with DNA repair gene expression in organisms. The results suggest that the low levels of expression for the 3 special genes (i.e., $X R C C 1, h O G G 1$, and $E R C C 1$ ) should be used an indicators of environmental pollution in animal populations.

$\mathrm{Cd}$ can also replace zinc in the zinc finger structure via nucleoside excision repair disorder, which has been previously reported (Shimizu et al., 2007). Cd is related to cellular transformation and carcinogenicity (Zhou et al., 2012). During the process of DNA replication, DNA clipping was insensitive to $\mathrm{Cd}$, but DNA polymerase and connecting were sensitive to Cd (Bertin and Averbeck, 2006; Hanova et al., 2010).

Compared to the control rat methylated sequences, the methylation levels of the 5 DNA repair gene promoters did not change after exposure to $\mathrm{Cd}$. We suggest that decreases in the RNA and proteins are caused by the fact that the DNA repair-related genes are not related to DNA methylation on the promoter. Other factors may affect DNA transcription and, therefore, further study is required.

\section{ACKNOWLEDGMENTS}

Research supported by the National Natural Science Foundation of China (\#81373038, \#81072322) and the Science and Technology Planning Project of Guangzhou Municipality, China (\#2013J410037).

\section{REFERENCES}

Al Bakheet SA, Attafi IM, Maayah ZH, Abd-Allah AR, et al. (2013). Effect of long-term human exposure to environmental heavy metals on the expression of detoxification and DNA repair genes. Environ. Pollut. 181: 226-232.

Benbrahim-Tallaa L, Waterland RA, Dill AL, Webber MM, et al. (2007). Tumor suppressor gene inactivation during cadmium-induced malignant transformation of human prostate cells correlates with overexpression of de novo DNA methyltransferase. Environ. Health Perspect. 115: 1454-1459.

Bertin G and Averbeck D (2006). Cadmium: cellular effects, modifications of biomolecules, modulation of DNA repair and genetoxic consequences (a review). Biochemie 88: 1549-1559.

Bhatnagar A (2004). Cardiovascular pathophysiology of environmental pollutants. Am. J. Physiol Heart Circ. Physiol. 286: H479-H485.

Bouziane M, Miao F, Ye N, Holmquist G, et al. (1998). Repair of DNA alkylation damage. Acta Biochim. Pol. 45: 191-202.

Fatur T, Lab TT and Filipic M.(2003). Cadmium inhibits of UV-, methyl methanesulfonate and N-methyl-N-nitrosoureainduced DNA damage in Chinese hamster ovary cells. Mutat. Res. 529: 109-116. 
Hake SB, Xiao A and Allis CD (2004). Linking the epigenetic 'language' of covalent histone modifications to cancer. $\mathrm{Br}$. J. Cancer 23: 761-769.

Hanova M, Stetina R, Vodickova L, Vaclavikova R, et al. (2010). Modulation of DNA repair capacity and mRNA expression levels of XRCC1, hOGG1 and XPC genes in styrene-exposed workers. Toxicol. Appl. Pharmacol. 248: 194-200.

Hartwig A (1998). Carcinogenicity of metal compounds: possible role of DNA repair inhibition. Toxicol. Lett. 102-103: 235-239.

IARC (1993). Beryllium, cadmium, mercury, and exposures in the glass manufacturing industry. In: Monographs on the evaluation of carcinogenic risks to humans. Vol. 58. International Agency for the Research on Cancer, Lyon, 119-238.

Joseph P, Lei YX and Ong TM (2004). Up-regulation of expression of translation factors - a novel molecular mechanism for cadmium carcinogenesis. Mol. Cell Biochem. 255: 93-101.

Kasprzak KS (2002). Oxidative DNA and protein damage in metal-induced toxicity and carcinogenesis. Free Radic. Biol. Med. 32: 958-967.

Klaassen CD, Liu J and Choudhuri S (1999). Metallothionein: an intracellular protein to protect against cadmium toxicity. Annu. Rev. Pharmacol. Toxicol. 39: 267-294.

Koyu A, Gokcimen A, Ozguner F, Bayram DS, et al. (2006). Evaluation of the effects of cadmium on rat liver. Mol. Cell Biochem. 284: 81-85.

Lehmann AR (1995). Workshop on eukaryotic DNA repair genes and gene products. Cancer Res. 55: 968-970.

Lu Q, Lei YX, He CC and Lei ZN (2013). Blood translation elongation factor-1 $\delta$ is a novel marker for cadmium exposure. Int. J. Mol. Sci. 14: 5182-5197.

Manca D, Ricard AC, Trottier B and Chevalier G (1991). Studies on lipid peroxidation in rat tissues following administration of low and moderate doses of cadmium chloride. Toxicology 67: 303-323.

Misra RR, Smith GT and Waalkes MP (1998). Evaluation of the direct genotoxic potential of cadmium in four different rodent cell lines. Toxicology 126: 103-114.

Nordberg G, Jin T, Bernard A, Fierens S, et al. (2002). Low bone density and renal dysfunction following environmental cadmium exposure in China. Ambio 31: 478-481.

Peters JL, Perlstein TS, Perry MJ, McNeely E, et al. (2010). Cadmium exposure in association with history of stroke and heart failure. Environ. Res. 110: 199-206.

Potts RJ, Bespalov IA, Wallace SS, Melamede RJ, et al. (2001). Inhibition of oxidative DNA repair in cadmium-adapted alveolar epithelial cells and the potential involvement of metallothionein. Toxicology 161: 25-38.

Satarug S, Baker JR, Urbenjapol S, Haswell-Elkins M, et al. (2003). A global perspective on cadmium pollution and toxicity in non-occupationally exposed population. Toxicol. Lett. 137: 65-83.

Schöpfer J, Drasch G and Schrauzer GN (2010). Selenium and cadmium levels and ratios in prostates, livers, and kidneys of nonsmokers and smokers. Biol. Trace Elem. Res. 134: 180-187.

Shimizu K, Onishi M, Sugata E, Sokuza Y, et al. (2007). Disturbance of DNA methylation patterns in the early phase of hepatocarcinogenesis induced by a choline-deficient L-amino acid-defined diet in rats. Cancer Sci. 2007: 1318-1322.

Singh KP, Kumari R, Pevey C, Jackson D, et al. (2009). Long duration exposure to cadmium leads to increased cell survival, decreased DNA repair capacity, and genomic instability in mouse testicular Leydig cells. Cancer Lett. 279: 84-92.

Swaddiwudhipong W, Mahasakpan P, Funkhiew T and Limpatanachote P (2010). Changes in cadmium exposure among persons living in cadmium-contaminated areas in northwestern Thailand: a five-year follow-up. J. Med. Assoc. Thai. 93: 1217-1222.

Van Duin M, de Wit J, Odijk H, Westerveld A, et al. (1986). Molecular characterization of the human excision repair gene ERCC-1: cDNA cloning and amino acid homology with the yeast DNA repair gene RAD10. Cell 44: 913-923.

Waalkes MP (2003). Cadmium carcinogenesis. Mutat. Res. 533: 107-120.

Waalkes MP and Poirier LA (1984). In vitro cadmium-DNA interactions: cooperativity of cadmium binding and competitive antagonism by calcium, magnesium, and zinc. Toxicol. Appl. Pharmacol. 75: 539-546.

Waisberg M, Joseph P, Hale B and Beyersmann D (2003). Molecular and cellular mechanisms of cadmium carcinogenesis. Toxicology 192: 95-117.

Wang GP and Xu CS (2011). Alterations in DNA repair gene expression and their possible regulation in rat-liver regeneration. Genet. Mol. Biol. 34: 304-309.

Zhou T, Jia X, Chapin RE, Maronpot RR, et al. (2004). Cadmium at a non-toxic dose alters gene expression in mouse testes. Toxicol. Lett. 154: 191-200.

Zhou ZH, Lei YX and Wang CX (2012). Analysis of aberrant methylation in DNA repair genes during malignant transformation of human bronchial epithelial cells induced by cadmium. Toxicol. Sci. 125: 412-417. 